\title{
Análisis crítico de la redefinición de "ideología" en el pensamiento político contemporáneo
}

\section{(Critical analysis of "ideology" redefinitions within contemporary political thought)}

\author{
Matías GonzÁLEZ \\ Universidad de Murcia \\ fermatgon@gmail.com
}

Recibido: 9 de marzo de 2011

Aceptado: 21 de octubre de 2011

\section{Resumen}

El presente trabajo analizará una serie de esfuerzos teóricos recientes vinculados a la posible redefinición y aprehensión conceptual de los fenómenos de ideología en las sociedades contemporáneas. El estudio desplegará algunos de los problemas que se presentan al interior de esta clase de esfuerzos conceptuales, enfocando especialmente en el contexto del pensamiento político de raíces postestructurales y lacanianas. Se observará, en suma, el modo en que dichas redefiniciones confrontan con ciertas dificultades o generan tensiones conceptuales debido al tipo de presupuestos epistémicos más vastos desde los que las búsquedas parten. La puesta en relieve y el análisis de algunos de estos problemas constituye el objeto principal del presente estudio.

Palabras clave: ideología, análisis del discurso, postestructuralismo, historia conceptual.

\section{Abstract}

This paper analyzes a number of recent theoretical contributions concerning the possible redefinition and conceptual grasp of ideological phenomena in contempo- 
rary societies. The study will display some of the problems that arise within this kind of conceptual efforts, focusing especially on the context of poststructural and Lacanian political thought. The work will consider how such redefinitions confront with difficulties or conceptual tensions resultant from the vaster epistemic grounds within which such efforts are located. The highlighting and analyzing of some of these problems is the main focus of this study.

Keywords: ideology, discourse analysis, poststructuralism, conceptual history.

\section{Introducción}

Hay cosas que parecen simples, pero que se complican al querer sintetizarlas en una definición [respecto del tiempo]

San Agustín

A continuación se argumentará a favor de la importancia de un estudio de lo ideológico a través de un tipo de operación histórico-conceptual e histórico-intelectual en el pensamiento político contemporáneo. En términos sintéticos, el hilo conductor del trabajo se desplegará a través del análisis de distintas respuestas contemporáneas o intentos de recuperación de una "crítica de la ideología" como categoría analítica una vez que "lo otro" de la ideología en su sentido clásico - es decir, la eventualidad de una visión "clara, verdadera, no distorsionada"- ha sido gravemente cuestionado, "conmovido", en el curso del siglo recientemente pasado. El recorrido del artículo comenzará con una introducción relativa a los procesos de sentido desde un punto de vista histórico conceptual -que servirá para establecer el espacio problemático general-, seguido por la reconstrucción de diversas intervenciones sobre la cuestión ideológica que integrará análisis de autores como S. Žižek, E. Laclau, E. Palti y M. Jay, entre otros. El conjunto permitirá poner de relieve algunas de las aristas más problemáticas con las que se enfrentan en la actualidad los estudios en el tema.

\section{Conceptualidad ideológica}

Cómo pensar la conmoción cuando las categorías con las que pensamos forman parte de lo conmovido?

Michel de Certeau

Tal vez un trabajo de R. Koselleck en torno al concepto de "revolución" pueda servirnos a modo de introducción. Si bien hay pocas palabras -sostiene este autor- 
que se hayan difundido tan ampliamente en el vocabulario político moderno como la expresión "revolución", su sentido -como es de esperarse- ha estado lejos de ser unívoco. De todas maneras, remontar en el tiempo la historia de este concepto más allá de la Revolución Francesa, permitiría "resaltar algunas particularidades de nuestra experiencia moderna" logrando "de ese modo, poder reconocerla con mayor claridad". 1

En 1842 -sostiene Koselleck- un ilustrado francés recordó algo que se había olvidado para ese entonces, que el término revolución denotaba un regreso, un "movimiento circular", que era en aquel tiempo incomprensible pero que anteriormente habría sido la base de posibilidad semántica con la cual debía a su vez entenderse la teoría antigua de las formas de gobierno (que se suceden unas a otras en un ciclo semejante al movimiento de las estaciones del año). Esta metáfora natural subordinada al concepto de revolución estuvo ligada a su vez a la obra de Copérnico de revolutionibus orbium celestium sobre los movimientos circulares de los cuerpos celestes de 1543, fenómeno que habría dado lugar a una contaminación semántica entre astrología y política. En sintonía con su enfoque histórico conceptual, algunas de estos contenidos semánticos -entiende Koselleck- han continuado resonando en el uso posterior del lenguaje. De todos modos, la tonalidad "natural" de la revolución descansaba sobre un supuesto (el de la repetibilidad o permanencia cualitativa de un mismo tiempo histórico) que posteriormente sería removido. Dicha posibilidad de resonancias o ecos semánticos forjados en otros universos de sentido sería entendida entonces como posibilidad de tematizar la "simultaneidad de lo asincrónico"; contemplar de qué manera residuos espectrales de significado reaparecen en un nuevo horizonte concreto en torno a nuevas articulaciones de sentido. Esto es, de qué manera, en su propio plano, dichos horizontes de sentido o "suelos de inteligibilidad" se sucederían unos a otros no sólo al interior de un principio de irreversibilidad temporal2 sino que parte de sus relaciones mutuas son pasibles de un análisis a través de los desplazamientos y pasajes de elementos articulados por dicha diferencia-lidad que los separa y los une en su sentido histórico - como parte de los procesos de una sobredeterminación y "ono-semasiología" en una Begriffsgeschichte.

\footnotetext{
1 Koselleck (1993, p. 69). Un argumento análogo puede encontrarse en Quentin Skinner en torno a la noción de libertad: "By writing about the history of freedom in this way, we can hope to uncover the ideological forces at work both in the original construction of the concept and in its subsequent undermining and replacement. This in turn enables us to see our modern liberal concept of freedom is just that -it is our concept, and a rival to a concept that has largely been lost to sight". Skinner (2005, pp. 34-5). Véase también Skinner (2007). Para una sugerente consideración de la Begriffsgeschichte, dentro de la cual Koselleck es sólo una de sus figuras salientes, véase también la introducción de Villacañas y Oncina a Koselleck y Gadamer (1997).

2 En tanto que una formación no se sigue necesariamente de su antecesora pero sobre ésta se apoya y se despliega -lo cual se distingue de una noción de progreso.
} 
Hasta aquí, toda idea de emancipación social ligada al concepto de revolución se encontraba ausente, sencillamente no formaba parte de su campo de experiencia. Luego de un recorrido a través de los desplazamientos semánticos operados sobre el concepto -en virtud de complejas vicisitudes- pasando por el siglo XVIII ilustrado y un viraje semántico ulterior hacia una idea de "dirección sin retorno" (la cual se consolidará firmemente a partir de 1789) Koselleck concluye reseñando algunas características propiamente modernas de "revolución", entre ellas: su concentración en un singular colectivo, la experiencia de la aceleración, el contenido (finalmente) de "emancipación social", su producibilidad, etc. Así, puede decir este autor, "cuando el joven Marx acuñó la formulación dualista de que una revolución descompone la sociedad anterior en la medida en que es social. Una revolución derriba el poder anterior en la medida en que es política, estaba formulando como principio universal algo que sólo era posible pensar a partir de 1789 ". ${ }^{3}$ En este punto tal vez pueda verse la cercanía de esta perspectiva teórica con otros enfoques contemporáneos considerados, como el estudio de los lenguajes políticos de la escuela de Cambridge. Ese trasfondo de otro nivel de discurso, la consideración no sólo de lo que un autor-actor dice sino del sistema de presupuestos que hace posible que tal cosa sea pensada, vista, o mencionada. Y otro tanto ha podido decirse respecto a toda posibilidad de identidad, la cual, en todo caso, deberá "realizarse" -o bien sería una suerte de "prestación". En este sentido, los "distintos accesos antropológicos" a la retórica convergerían en que "hasta para nosotros mismos, somos algo fenoménico", una "síntesis secundaria de una multiplicidad primaria, no a la inversa, una síntesis primaria de una multiplicidad secundaria": "Kant fue el primero en negar que la experiencia interior llevara la delantera a la experiencia exterior": la autocomprensión tendría, según se dirá, "la estructura de la autoexterioridad". 4

Veamos ahora, en un ejercicio de refracciones diversas, una serie de abordajes a la cuestión de "lo ideológico". Comencemos por el influyente El espectro de la ideología en el cual S. Žižek propone marcar una clara distancia con respecto a enfoques afines a los planteados en nuestra introducción, vinculados, podría decirse, a lo que según la terminología del autor serían consideraciones con excesiva atención en la dimensión "diacrónica" de las categorías. No obstante, es posible que las referencias implícitas a las que hace alusión dicho autor se encuentren algo más próximas al contexto de reflexión desde el que el mismo parte, como sería por ejemplo el tipo de trabajo desarrollado por E. Laclau y C. Mouffe en torno al concepto de "hegemonía" al interior de la tradición marxista. Se recordará que dicho trabajo se mostraba preocupado en "mostrar la contingencia originaria de aquellas síntesis que las categorías marxistas intentaban establecer" y, en lugar de adherirse a nocio-

\footnotetext{
3 Koselleck (1993, p. 78).

4 Blumenberg (1999, p. 141).
} 
nes tales como "clase", "fuerzas y relaciones de producción", etc., (como a "fetiches sedimentados") lo que intentaba era "revivir las precondiciones que hicieron posible su operatividad discursiva". 5 En parcial consonancia con este campo de discurso, Žižek realizará una serie de propuestas en torno a la noción de ideología que merecen un momento de atención. Antes de avanzar en el tema planteado en términos de diacronía y sincronía, veamos brevemente algunas aproximaciones ensayadas por el autor con respecto a una posible delimitación de lo estrictamente "ideológico" en un contexto filosófico actual. En una de sus primeras manifestaciones se destaca la importancia contemporánea de la ideología en tanto "matriz generativa que regula la relación entre lo visible y lo no visible, entre lo imaginable y lo no imaginable, así como los cambios producidos en esta relación" -formulación que, en principio, abriría el campo de las aproximaciones a lo ideológico hacia una diversidad muy rica de recursos conceptuales. ${ }^{6}$ De todas maneras, en un momento ulterior del análisis se intenta encontrar alguna especie de norma que permita establecer fundadamente lo que es o debería ser la ideología y su "otro", cerrando en cierta medida esa amplitud inicial. Aparecen en principio dos elementos alrededor de los cuales las conjeturas se movilizan. El primero podría ser entendido como elemento propio de la "intencionalidad" o de la mala fe; 7 y el segundo (a su vez como condición de posibilidad del primero) determinado por la diferencia entre el falso reflejo invertido y las verdaderas relaciones de poder -el cual puede extenderse a la versión más amplia del binomio "correcto"/ "incorrecto".

Estas primeras orientaciones de un campo de referencia no impiden sin embargo que, llegado el momento, el argumento comparta la perspectiva crítica del "análisis del discurso" -inspirada en diversos conceptos del psicoanálisis- según la cual lo ideológico por excelencia sería "la noción misma de un acceso a la realidad sin el sesgo de dispositivos discursivos o conjunciones con el poder". ${ }^{8}$ Cabría preguntarse, desde este punto de vista ¿en qué consistiría entonces aquella norma según la cual el campo de lo ideológico aparecería delimitado por la presencia de elementos discursivos funcionales a una relación de poder? ¿Cómo se definirían las líneas que ordenan las diferenciaciones que el argumento en este contexto requiere? En definitiva, estos trazos esbozados hasta aquí no parecen colaborar con una pretendida

\footnotetext{
5 Laclau y Mouffe (2006, p. 8).

6 Žižek (2003b, p. 7).

7 La ideología funciona aquí como "legitimación 'objetivamente cínica' (Marx) de la relaciones de poder existentes” (Ibid, p. 15). Véase también (Ibíd, p. 22 y p. 28). El ejemplo dado sería el de una potencia extranjera que interviene un país del tercer mundo alegando hacerlo en defensa de derechos humanos supuestamente violados en el mismo, lo cual puede ser efectivamente cierto (y esto proveería de mayor fuerza al discurso) sin por esto dejar de ser ideológico pues los motivos verdaderos de la intervención pueden ser otros (intereses económicos, de dominación, de poder, etc.).
}

8 Žižek (2003b, p. 18). 
delimitación del fenómeno. Ingresemos, por lo tanto, en la parte más elaborada del proceso de fundamentación de un nuevo concepto de ideología. ${ }^{9}$

Para empezar, Žižek esboza las líneas de un primer tipo de abordaje posible al tema -el cual se ajustaría, según sostiene, a "la transposición histórico-dialéctica hegeliana del problema en su propia solución: en lugar de evaluar directamente la adecuación o la 'verdad' de las diferentes nociones de ideología, uno "debería leer esta multiplicidad misma de determinaciones de la ideología como una señal de diferentes situaciones históricas concretas". 10 A continuación, el autor traza dos ejemplos de esta alternativa. El primero hace referencia al desplazamiento semántico operado en la noción de ideología a fines de la década de 1920, cuando el leninismo estalinismo adoptó el término "ideología proletaria" para designar la fuerza subjetiva propia de la actividad revolucionaria y no ya la "distorsión" de la conciencia proletaria por la ideología burguesa; el segundo tematiza la diferencia entre la crítica de la economía política (Lukács) y la crítica de la razón instrumental de la Escuela de Frankfurt -desplazamiento que se describe como enmarcado en el espacio histórico abierto luego del doble trauma de fines de la década de 1930 y 1940 : la regresión de las "sociedades capitalistas hacia el fascismo y el giro 'totalitario' del movimiento comunista".

Luego de esbozar ligeramente estos ejemplos de un posible enfoque que contemple ciertos elementos de historicidad, el autor decide desecharlo ya que, según cree: "Un abordaje como ese puede hacernos caer fácilmente en la trampa del relativismo historicista que suspende el valor cognitivo inherente del término 'ideología' y lo transforma en una mera expresión de las circunstancias sociales". ${ }^{11}$ En buena medida, según intentaremos observar, ese peligro del que intenta alejarse el autor aparecerá cumpliendo una función precisa en la economía de su discurso.

Žižek explicita a continuación su opción por un abordaje al que llama "sincrónico" y propone una posible clasificación tripartita -de inspiración hegeliana- de la ideología en tres ejes: como "doctrina" o complejo de ideas (creencias, conceptos, convicciones, teorías, etc.); como "ritual", la materialidad de la ideología en su exteriorización/otredad (ej: los Aparatos ideológicos de Estado, AIE) y, por último, como "creencia" - en términos hegelianos-, ese terreno elusivo de la ideología espontánea operando silenciosamente en el corazón de la realidad social (el ejemplo aquí es el fetichismo de la mercancía en Marx). Detengámonos en el primero de sus ejes, al que se caracteriza como un complejo de ideas o creencias cuyo fin es disimular una verdad inconfesa al servicio de una relación de poder. La crítica de la ideología correspondiente a esta noción sería la que se denomina "lectura de síntomas", y que se abocaría a "descubrir" esa verdad no confesada en el texto oficial a

9 "La pregunta inicial [concierne] al concepto de ideología" Žižek (2003b, p. 14).

10 Žižek (2003b, p. 15).

11 Žižek (2003b, p. 16). 
través de sus impasses, deslices, sus silencios etc. Habermas se presentaría aquí como el último gran representante de esta tradición de pensamiento, quien sostendría la posibilidad de una comunicación racional, "normal" no distorsionada por tales intereses de dominación social. No obstante en la actualidad, argumenta Žižek, la tendencia más prestigiosa de la crítica de la ideología -surgida del "análisis del discurso"- paradójicamente invierte esta relación: la idea de un acceso a la realidad no mediada discursivamente consistiría la posición ideológica por excelencia -en otras palabras, se cuestiona la posibilidad misma de un punto de mira metalingüístico; "lo que Habermas percibe como apartamiento de la ideología es denunciado aquí como ideología por excelencia"; 12 para luego mencionar a otros autores, entre ellos a M. Pêcheux, indicando de qué manera "los hechos nunca hablan por sí mismos" sino que sólo pueden hacer tal cosa (ser percibidos) "contra el fondo de un espacio preconstituido discursivamente". 13

La primera inquietud que surge del argumento resulta de la modulación planteada en el mismo respecto a este suelo "discursivo" que parece hasta entonces compartido pero del cual se intenta distanciar parcialmente al observar en él ciertas consecuencias desagradables para sus propios intereses teóricos. En ese orden de ideas, se volverán a invertir las acusaciones: la conclusión de "que la única posición no ideológica es renunciar a la noción misma de realidad extraideológica y aceptar que todo lo que tenemos son ficciones simbólicas, una pluralidad de universos discursivos, nunca la "realidad"” es, según se asegura, una solución "ideológica por excelencia". La contrapropuesta a dicha solución consistirá en "mantener" esa posición inaccesible pero necesaria, "debemos sostener la tensión que mantiene viva la crítica de la ideología": "es posible suponer una posición que nos permita mantener una distancia con respecto a ella, pero este lugar desde el que se puede denunciar la ideología debe permanecer vacio, no puede ser ocupado por ninguna realidad definida positivamente. En el momento en que caemos en esa tentación, volvemos a la ideología". ${ }^{14}$ Llegado este punto, según intentaremos observar, los argumentos

12 Žižek (2003b, p. 18).

13 Žižek (2003b, p. 19). En palabras de Laclau y Mouffe, "toda 'experiencia' depende de condiciones discursivas de posibilidad precisas", donde además el nexo con una historia conceptual se vuelve particularmente visible. El ejemplo de Žižek aquí era: "Cuando un inglés racista dice '¡Hay demasiados paquistaníes en nuestras calles!, ¿cómo - desde qué lugar- 've' esto? Es decir, ¿qué hay en la estructuración de su espacio simbólico que lo haga percibir como un exceso perturbador el hecho de que un paquistaní camine por una calle de Londres?"; Laclau y Mouffe (2006, p. 156); y Žižek, (2003b, p. 19). Resulta de gran interés la eventual aplicación del aparato de análisis de una historia intelectual para abordar fenómenos de naturaleza semejante -es decir "sociales" actuales, identitarios, incluso culturales, en la terminología contemporánea. Véase por ejemplo, el texto de Blas de Santos (2006) que ha sido leído en ciertos contextos como un punto de partida en esta dirección, es decir, en cuanto análisis histórico de la configuración de la subjetividad militante de los años 60 y 70.

14 Žižek, (2003b, p. 26). 
podrían comenzar a acercarse a una puesta en cuestión del suelo de premisas que subtienden al sistema en que se despliega su propio discurso; o incluso, en cierto modo, ¿con qué clase de fundamentos se podría evitar que la lógica implícita en su desarrollo se vuelva luego sobre sí misma? ¿No se estaría generando un cierto espacio argumental que abriría las puertas a un "relativismo" del cual justamente se intentaba huir? Por el momento dejemos aquí estas disquisiciones para retomarlas más adelante y observar de qué manera este tejido argumental se encontraría apoyado en una serie de tensiones y aporías muy particulares. Antes, desplacemos el campo de referencia y observemos ciertas particularidades vinculadas a una aproximación a la significación y a los procesos a ella vinculados. Encontraremos ulteriormente a partir de las siguientes reflexiones tres aspectos que serán útiles para nuestro tema de interés: el primero se vincula a un conjunto de elementos que hacen a una aproximación de mayor complejidad crítica a los procesos de sentido; el segundo a una problematización de los "puntos de mira" al interior del paradigma de la lingüisticalidad; y el último guarda relación con los anteriores en cuanto dicho eje lingüístico (el cual será ilustrado en refracción con uno de los campos de reflexión en que sus principios han sido llevados hasta sus últimas consecuencias lógicas) forma parte del horizonte epistémico más amplio dentro del cual los aportes postestructurales se encuentran operando. En la introducción misma de Hegemonía antes mencionado se habla de una gran rotación intelectual operada en el curso del siglo $\mathrm{XX}$ a través de los ejes: lingüístico, postestructural, del psicoanálisis y las epistemologías.

\section{Los avatares de la lingüisticalidad}

Observemos entonces un instante la problemática de la crítica tal como puede seguirse en el movimiento reflexivo del llamado "giro lingüístico" en la historia intelectual -dinámica en la cual se problematiza renovadamente la posibilidad de un "punto de mira arquimédico".

La lógica de este movimiento puede ser presentada, siguiendo a E. Palti, como aquella en la cual se torna objeto de crítica -de manera sucesiva y renovada- el suelo de premisas que subyacen incuestionadas a un cierto horizonte de discursividad dado (esto es, se tematiza aquello que permanecía impensado dentro de cada espacio de inteligibilidad). ${ }^{15}$ Es importante destacar que la relación entre los distin-

\footnotetext{
15 Véase Palti (1998), en donde el autor desarrolla este movimiento con profundidad en términos de "tematización-problematización-rebasamiento" inspirado en los conceptos de J. Piaget y R. García. Véase también Jay (2003), en el cual se trabaja la misma problemática con algunas diferencias en la estructuración formal -éste brinda una presentación más arbórea de los autores aunque menos profunda, haciendo además un contrapunto con la desconstrucción.
} 
tos momentos o fases de esta dinámica no correspondería al de una jerarquía lógica, "el paso de uno a otro implicaría, sencillamente, un desplazamiento del campo bajo observación". 16

El punto de inicio de esta dinámica -de reaparición de aporías- es presentado a través de la trayectoria intelectual de Q. Skinner a partir de su intervención frente a la vieja historia de ideas, en virtud de la cual comenzarán a tematizarse -y luego problematizarse- las relaciones entre un texto dado y su "contexto de emergencia". Esto es, dicho rápidamente: no se puede comprender la intencionalidad de un texto (entendido como un "acto de habla" en sentido austineano) de Maquiavelo por ejemplo, sin considerar sus "condiciones semánticas de producción" (estrategias retóricas y polémicas, mecanismo discursivos, sistemas de autoridades etc.). Esto llevará a su vez a la tematización de ese mismo texto y su "contexto de recepción" (ya no se trataría de Maquiavelo y su mundo sino de Skinner y el suyo): el contexto histórico de producción de la propia crítica. El movimiento siguiente -el cual es emblematizado a través del paso de la antropología geertziana a la post-geertzianaes el que tematiza las "condiciones de recepción" de la propia crítica, los discursos críticos: "cómo estos pueden formarse, intercambiarse y circular socialmente, cómo el propio mundo de Skinner se articula como un texto, abierto, por lo tanto, a distintas lecturas posibles. Y ello nos arroja, finalmente, de lleno al contexto epistémico-institucional en que se desenvuelven las disciplinas"17 (una referencia aquí es Stanley Fish). Comienza así a tematizarse el "contexto metacrítico", con lo cual la propia noción de texto comenzaría a disolverse.

En realidad, como muestra Palti a través del análisis de diversos autores (Rorty, Bernstein, etc.) abocados a "problematizar" este umbral metaconceptual: "Llegado a este punto, la única salida parece consistir en establecer una diferencia de niveles de discurso [...] a fin de producir una clausura metacrítica: lo que sería valido a un nivel de discursividad no sería aplicable al propio discurso metacrítico" 18 -y esto terminaría conduciendo en cada caso a contradicciones insolubles; o bien negarse a dar cuenta de los propios fundamentos, es decir abrir la senda del "relativismo".

Una vez que la crítica se convierte en metacrítica, sus modos de validación se reformulan: "ya la legitimidad de la misma no se fundaría en poder justificar la posibilidad de acceder a un significado 'oculto' tras los textos, sino en su capacidad para dar cuenta de sus mismos fundamentos teóricos", sólo entonces "surge el problema epistemológico mas general de la posibilidad de pensar una teoría que pueda, al mismo tiempo, aplicarse, sin contradicción, a sí misma (es decir de una teoría que contenga su propia metateoría)". ${ }^{19}$ A partir de entonces, esta tensión entre necesi-

\footnotetext{
16 Palti (1998, p. 160).

17 Palti (1998, p. 162).

18 (Ibid., p. 162).

19 (Ibid., p. 64).
} 
dad e imposibilidad de una metacrítica atravesaría centralmente todo desarrollo teórico producido dentro de los marcos de este giro lingüístico. Ese lugar imposible y necesario, esa " $x$ " inaccesible minaría secretamente todo intento de establecerla $u$ ocluirla a través de una fijación textual que escape a su propia contingencia. La imposibilidad de la auto-aplicación de los principios de la lingüisticalidad de manera venturosa llevaría entonces a la confrontación con un límite, con un punto ciego del cual no podría darse cuenta desde el interior de dicho horizonte.

En suma, las "relaciones" que se van problematizando en esta dinámica según lo observado, podrían ilustrarse en el siguiente movimiento de izquierda a derecha:

1) texto --- "contexto de emergencia"/ texto --- "contexto de recepción"

2) crítica --- "contexto de emergencia"/ crítica --- "contexto de recepción"

3) critica --- "contexto metacrítico"/ "x"

Esto es:

texto --- c.e. / texto --- c.r.

(crítica)

texto' --- c.e. / texto' --- c.r.

(texto)disolviéndose

disciplinas --- c.m. / "x"

Dentro del campo de las reflexiones narrativas, Lyotard diría que: "La inspiración bajo los discursos teóricos [...] es evitar que olvidemos el Bien, Dios, el Ser, el Trabajo, el Inconsciente, el Tiempo. El precepto detrás de la teoría [...] es la necesidad de luchar contra el olvido; por eso decimos que es una meta-narrativa: una narrativa sobre el recordar historias. Pero incluso esa meta-narrativa se ve forzada a olvidar algo, olvida que es una narrativa. Ese es el tributo que paga el tiempo". ${ }^{20}$

En un sentido más cercano al contexto de referencia, una circunstancia problemática similar podría ilustrarse mediante una dimensión (meta) lingüística analizada en el mismo texto lacaniano. Partamos de la difícil diferencia, si acaso no estamos en el seno de un punto pasible de redescripciones y usos de sentidos alternativos según sean las necesidades (o intereses) discursivas en cada caso, entre "reduccionismo", por un lado, y "analogías" (o "extensiones" a su vez inevitables e inmanentes al trabajo del texto -en sentido derrideano- no sólo humanístico o filosófico sino propio de los mundos científicos), por el otro. Partamos, por ejemplo, de la crítica desde ciertos científicos sociales a posibles lecturas o análisis que tratan a la sociedad como a un paciente -o como poseedora de un inconsciente, un superyó, de desórdenes patológicos, etc.- crítica a su vez compartida por Lacan. Como observa J. Stavrakakis (quien también comparte dicha lectura) de todos modos, en un sentido epistemológico más general, en tanto toda operación de análisis presupone la

20 Benjamin (1989, p. 145). 
elucidación de un cierto problema o campo a través de una referencia a algún elemento externo al mismo, y por lo tanto la articulación de un metadiscurso, en todo análisis puede hablarse de alguna dimensión de reduccionismo -en dirección, se puede entender, al proceso extensible a un fenómeno de analogías (metafóricas, en un plano cargado antropológicamente) en el desarrollo de diversos lenguajes, o incluso en un plano hermenéutico mínimo como en la lectura de un texto, nunca exenta de una introducción de elementos, y asociación a (o "en") sistemas ajenos al mismo. Pero al mismo tiempo ningún metalenguaje puede articularse de un modo cerrado o autocontenido. Para Lacan, una posición metalingüística es necesaria (todo lenguaje es un metalenguaje) e imposible a la vez (ningún metalenguaje es posible), en tanto toda formalización metalingüística del lenguaje debe emplear el lenguaje mismo y por lo tanto su carácter puro se ve minado. Por lo tanto, se entiende que "No hay metalenguaje", pero, a su vez, si esta determinación de una negación se presentara planteada como desde el exterior al mismo, entonces la fantasía de evitarlo en su totalidad de una vez permanecería intacta. La propia posición de la negación se ve afectada inmanentemente. La operación metalingüística con la que Lacan plantea la imposibilidad de un metalenguaje es a su vez presupuesta como una operación fallida. "Cuando lidiamos con problemas de reduccionismo, esencialismo y otras categorías similares -sostiene Stavrakakis- desde un punto de vista lacaniano es necesario evitar posiciones absolutas -'absolutismo' presupone represión-e introducir ciertos juegos de lenguaje que permitan una aproximación más sutil pero efectiva para confrontar el problema". ${ }^{21}$

Volviendo ahora al contexto de Žižek, recordemos su supuesta "salida" a la secuencia de repliegues o acusaciones renovadas de "ideología por excelencia" en un movimiento reiterado que se presentaba -según hemos visto- de Habermas al análisis del discurso y de éste a la acusación del propio Žižek sobre su carácter ideológico. Aquella consistía, según el argumento, en "mantener" esa posición vacía, sostener la tensión que nos permita una "crítica de la ideología", ese lugar in-ocupable, etc. Contexto en el que se comenzarán a explicitar algunos conceptos psicoanalíticos para definir formalmente lo que se llamará el "núcleo pre-ideológico" de la ideología, ese lugar "sobre el cual" se habrían "sobreimpreso diversas formaciones ideológicas"; consistente en la "aparición espectral que llena el hueco de lo real". ${ }^{22}$ La ideología estaría vinculada, pues, a la oclusión (imposible) de lo Real que toda configuración simbólica u horizonte debe realizar para constituirse. 23

21 Stavrakakis (1999, pp. 141-2).

22 Žižek (2003b, p. 31).

${ }^{23}$ El problema en último término se desplazará en este caso al nexo entre dicha eventual condición de la vida simbólica y la posibilidad de fundar conceptualmente y ejercer una crítica ideológica en sentido tradicional. El que todo horizonte de sentido se base en operaciones precarias -o pragmáticas - no implica necesariamente un fundamento para distinguir a la ideología de su "otro" en el sentido en que el autor lo desarrolla. 
Resulta en cierta medida de utilidad, para terminar de comprender algunos aspectos del argumento de Žižek, que llevemos nuestra atención al plano de referencia dentro del cual su pensamiento se instala y sobre el que se mueven sus argumentaciones. Esto es, el horizonte de pensamiento "postestructural" -independientemente del supuesto debate acerca de una determinación de la obra de Lacan dentro de este concepto. En un contexto semejante, podría destacarse emblemáticamente a la deconstrucción y su "crítica a la metafísica" -en cuanto discurso orientado a tornar objeto de análisis y minar la serie de premisas que fundaban el tipo de discursividad abierto a fines del siglo XIX. Simultáneamente, otra de las características del suelo epistémico más amplio dentro del que tales desarrollos se desenvuelven se articularía al pasaje en virtud del cual "cambio y racionalidad" (sobre lo que Lévi-Strauss se habría expresado en más de una oportunidad) dejarían de aparecer como mutuamente excluyentes (minando así toda la serie de dicotomías derivadas); lo cual puede observarse como una asociación a una recomposición más general en los regímenes de saber occidental, o que no se reduce al pensamiento filosóficopolítico. Durante las últimas décadas, al menos en un sentido particular, en diferentes campos el objeto se habría desplazado hacia el cambio mismo entre sistemas radicalmente discontinuos -afectando a su vez la pregunta por el sujeto. Las ideas de metaevolución en biología (Maturana) y de acontecimiento en termodinámica (Prigogine) serían ejemplos de ello. O como diría A. Badiou en 1988: "Por lo general, al acontecimiento se lo arroja a la pura empiria de lo-que-adviene y se reserva la construcción conceptual para las estructuras. Mi método es inverso". ${ }^{24}$ Un elemento implícito en este caso sería la articulación del problema del punto inmanente de dislocación y constitución en la estructura -lo Real sería uno de sus términos asociados- y el problema de la temporalidad en el sentido observado. Desde este punto de vista, puede observarse por otra parte que los ejemplos de Žižek de un abordaje "diacrónico" formarían probablemente parte de un mismo suelo de saber, lo cual también evidenciaría la clase de referencia analítica, una cierta consideración de "historicidad" que permite un tipo de argumentación funcional a su economía discursiva. Lo importante por ahora consiste en ubicar al pensamiento "marxista" postestructural dentro de una reconfiguración más general de los regímenes de "visibilidad"; como fenómeno local aunque particularmente emblemático de una época que puede intentar narrarse como el espacio que se abre luego del Sentido. 25 A este espacio subyacería una substracción ineliminable que lo hace desplegarse como espacio imposible y necesario a la vez, pues siempre estará estructurado/desestructurado en torno a un vacío anterior/posterior a toda discursividad -el cual conectaría al sistema con su exterioridad pero que en sí no es sólo tal sino que lo habita y lo funda. Khôra, supernumerario, lo Real, antagonismo, excre-

24 Badiou (2003, p. 201).

25 Palti (2005). 
cencia, catacresis, serían algunos de los "nombres" vinculados a ese espacio signado por la imposibilidad y la necesidad de un centro, por la contingencia y la historicidad de sus fijaciones, por lo paradójico y aporético de su condición renovada.

Volviendo a nuestra línea argumental podría tal vez argumentarse -parafraseando a Koselleck- que: "cuando Žižek acuña ese 'núcleo pre-ideológico de la ideología', de alguna manera estaría formulando como principio universal algo que únicamente ha sido posible pensar a partir de un horizonte post-metafísico". Pero eso no sería lo realmente importante. El argumento ofrece además algunas otras notas acerca de lo que se considera tipificante de lo ideológico, "universal" de la ideología, por ejemplo respecto del componente diferencial: "no hay ideología que no se afirme a sí misma por medio de su demarcación respecto de otra 'mera ideología'. Un individuo sometido a la ideología nunca puede decir por sí mismo 'Estoy en la ideología', siempre necesita otro corpus de doxa para poder distinguir de ella su propia posición "verdadera"'. 26 Un ejemplo de esta operación sería la clásica subordinación platónica entre doxa y episteme. Comenzaría entonces lentamente a emerger una parte del problema o el tipo de situación conceptual con la que se intentaría lidiar y que recorre el texto en su extensión. Hemos observado inicialmente, en su propio nivel de discurso, algunos movimientos que cumplen ese requisito "universal" de subordinación binaria. Una primera prefiguración la encontramos desde el inicio respecto a un abordaje sincrónico frente a uno diacrónico -distinción que tendrá un lugar especial y conflictivo en el texto; el último estaría sesgado por un peligro, por la trampa del relativismo, mientras que el primero es presentado como el más conveniente y seguro. Se podría argumentar que la diferencialidad no es sólo una condición de la ideología, pero ese justamente sería parte del problema, dónde trazar la línea que divide a esa consideración. A partir de allí, puede empezar a verse prematuramente el modo en que a cada paso dado -según se dice- "nos encontramos hundidos hasta la rodilla" en pleno campo ideológico -aunque en un sentido probablemente extensivo al dado en el argumento. Otra operación -aún más clara e importante- se presenta a través de aquella toma de postura ante lo que se denomina "una solución posmoderna" e "ingeniosa" del análisis del discurso según la cual sólo tendríamos una pluralidad de ficciones simbólicas etc. -y de la cual se distancia en tanto ideológica por excelencia (doxa) frente a la propia posición "verdadera" (sostener ese lugar vacío, in-ocupable, etc.). Esta desestabilización en el texto muestra, en última instancia, de qué manera se reconoce el suelo sobre el que se encuentra operando pero aún así se persiste en articular los rasgos universales que a su vez se denuncia. Podría decirse que esto incluye al desarrollo, paradójicamente, en un registro parcialmente analogable al que su autor suele describir habitualmente como "cinismo" a través de P. Sloterdijk. ${ }^{27}$ Incluso podría darse que dicho

26 Žižek (2003, p. 29).

27 Žižek (2003a, p. 55). 
concepto comenzara a perder algunas de sus propiedades conceptuales y a encontrar una función necesaria en el universo discursivo que subyace a los argumentos que dan cuenta de él. Éste comenzaría a adquirir un nuevo matiz o a desdibujarse en su expansión. Lo cual reenvía la atención a ese "no lugar" que habita y funda al universo discursivo de operatividad sobre el que se desarrollan los argumentos de Žižek, ese terreno fenomenológico anterior al ego trascendental, el cual sería indecidiblemente anterior y posterior al campo de la discursividad. ${ }^{28}$ Dicha particularidad conllevaría a que, desde el interior de los marcos de la discursividad nos reencontremos con una nueva "x", con un nuevo punto límite. Esa misma "salida" entonces respecto a lo ideológico según la cual habría que "mantener" ese lugar vacío sin poder ser ocupado estaría ya siendo ocupado en el mismo momento en que pretende establecerlo. Como hemos observado para resaltar esta circunstancia en términos aún simples, esa posición estaría sesgada desde su inicio a través de una subordinación frente a lo que es "mera ideología". Lo cual simplemente duplicaría aquello que el mismo ha establecido como rasgo "universal" de un "individuo" dentro de la ideología -resultando en que dicha posición estaría operando como un lugar ocupado. Con lo cual la empresa deviene en un gesto vacío.

El problema se renueva permanentemente. De ahí que el argumento acerca de lo que no es doxa se pueda describir extensivamente como una operación de "clausura metacrítica", la cual es imposible sin introducir alguna forma de contradicción, pues intenta ocluir, reprimir una " $x$ " que la sujeta y subvierte al mismo tiempo. En último término se estaría llenando casilleros imposibles aún cuando se explicite en ese mismo acto la existencia de tales. En suma, habría otra "x" más allá de la "x" de "lo dicho" y sería justamente la que corresponde al nivel del decir: lo que sería válido en un nivel de discursividad (enunciado) no sería aplicable al propio discurso (enunciación).

Con respecto a su diferenciación entre abordajes diacrónicos y sincrónicos, puede verse ahora con mayor claridad la importancia consecuente que involucra el acto de obturación de enfoques destinados a tomar en cuenta la historicidad de la conceptualidad, aquello que de algún modo es aceptado en su nivel enunciativo, pero de lo que al mismo tiempo se intenta escapar. Como si, ocultando esa falta en el Otro, obliterando aquello que recuerda y tematiza la radical contingencia que subyace a la conceptualidad, se quisiera tapar la propia "falta", o al menos no tomarla tan radicalmente; no se pretende digamos -haciendo un uso extensivo de los términos de Badiou- "permanecer" en la "inmanencia de la crisis". Esta no problematización conducirá de todas maneras a encontrarse con aquello de lo que se intentaba escapar, a quedar atrapado en el propio gesto de una tentativa y esto se presentaría con mayor claridad en relación al universo más vasto de comprensión epocal, aquel en el cual -justamente- la importancia de la temporalidad de lo con-

28 Palti (2005). 
ceptual se ha tornado cada vez más relevante y se ha problematizado en sus múltiples implicancias. Lo cual no quiere decir que el argumento analizado no sea consciente de la naturaleza de los problemas con los que estaría lidiando, lo cual puede verse en sus conclusiones al respecto, cuando se observa que la noción de ideología en algún sentido se ha vuelto "demasiado fuerte", o incluso que "comienza a abarcarlo todo".

\section{Una réplica "discursiva"}

Nuevamente es E. Laclau quien, en otro desarrollo contemporáneo en el tema propone sin más y en continuidad con lo expuesto, un primer momento en el que la "ideología" se desdibuja en este nuevo horizonte de discurso, "muere" como categoría analítica debido a su expansión y es sustituida por nociones menos ambiguas como la de "discurso". Pero a ese primer momento opone un segundo (el de la resurrección) en el cual la noción de ideología aparece renovada o refundada como dimensión inherente a toda discursividad. La lógica paradójica de esta dimensión consiste en el juego entre lo universal (imposible, ausente, perdido) y lo particular del cual el primero sería un "efecto". Esto es, el nivel literal (lo universal) no existe sino como un efecto, creado a través del sentido figurado (lo particular) que a su vez "distorsiona" al primero, lo cual explica que la distorsión pase a ser "constitutiva".

La dimensión del cierre (universal) no estaría entonces simplemente ausente, sino que se entiende como la presencia de una ausencia. La operación ideológica consiste en atribuir a un elemento particular a través de una operación proyectiva esa imposible función de completitud que es inconmensurable con él. En suma, la operación de cierre es imposible (en razón de la dislocación constitutiva que se encuentra en la base de todo arreglo estructural) y necesaria (porque sin esa fijación ficticia de sentido no habría sentido en absoluto). "Por consiguiente lo único superable es la falsa creencia de que podemos aislar nuestras mediaciones retóricas y ver el mundo al derecho" diría Martin Jay, polemizando con el postestructuralismo. ${ }^{29}$ Pero la negación de un nivel metalingüístico no conlleva, desde este punto de vista, la imposibilidad de efectuar una crítica de la ideología, "lo que es imposible es una crítica de la ideología en cuanto tal; todas las críticas serán necesariamente intraideológicas". ${ }^{30}$ Refiriéndose al desplazamiento operado con respecto al althusserianismo -y produciendo una nueva inversión- Laclau concluye que: "Es posible mantener una frontera nítida entre el cierre (la auto-reproducción de las relaciones sociales) y las formas necesarias de no-reconocimiento que lo acompañan sólo en la

29 Jay $(2003$, p. 263).

${ }^{30}$ Laclau (2006, p. 13). 
medida en que hay un punto de observación metalingüístico desde el cual el cierre se muestra a sí mismo sin ningún pasaje subjetivo a través del no-reconocimiento. Pero si la existencia de ese punto de observación es ilusoria, el no-reconocimiento contaminará el cierre; y dado que el no-reconocimiento, la distorsión es universal, su otro (el cierre, la auto-transparencia) pasa a ser la principal forma de no-reconocimiento. En tal caso la distorsión es constitutiva de la objetividad social". ${ }^{31}$ Por lo tanto "ideológico" se entendería en este caso como el no reconocimiento (necesario) de ese inherente no-reconocimiento estructural. Ésta sería, pues, la forma apropiada de aproximación al funcionamiento del universo socio-simbólico, a la ideología y su otro. Lo cual, no obstante, según sea el punto de vista, podría llevar a reconducir la problemática en dirección al momento en el que la interrogación y posibilidad observada se detienen. En un reciente trabajo, B. Bosteels intentaría trazar posibles conclusiones siguiendo sus propias premisas, y que se replicarían en la modalidad del plano de enunciación que hemos observado en Žižek, no obstante la perspectiva de Laclau se muestra notablemente más consecuente en cuanto a la dimensión histórica de las categorías, de lo que el primero justamente intentaba escapar. En contrapunto crítico, Bosteels observa que "esta nueva doctrina" no haría otra cosa que intentar proporcionarse "a sí misma un parámetro infalible para redefinir la ideología en términos de un falso reconocimiento estructural". ${ }^{32} \mathrm{El}$ espesor de esta renovación tal vez pueda desprenderse mejor de otras argumentaciones críticas del mismo Laclau según las cuales, en la desactualizada noción de Althusser "la ideología se constituye a sí misma como objeto a través de su oposición a la ciencia: la determinación de la distorsión que las representaciones ideológicas acarrean $[. .$.$] depende del conocimiento que el analista tiene de lo que la reproducción$ social realmente es". ${ }^{33}$ Se puede observar entonces el desplazamiento por el propio modo según el cual una justa comprensión de lo social bajo el no-reconocimiento como condición constitutiva implicaría una modalidad compuesta de reconstrucción "ideológica" -aprovechando la ambigüedad que permite el "no-reconocimiento". Es decir, el desplazamiento en el argumento de Laclau -apoyado en algunos caracteres de un horizonte discursivo post-estructural-para una redescripción de lo "propiamente ideológico" y su contra-crítica permiten especialmente observar que el concepto de ideología tendería a desplazarse entre distintos niveles discursivos -se entiendan en términos políticos, teóricos, epistémicos, etc.- que proveen de una variedad y riqueza particular a su dinámica. Al quedar traducido a un plano de generalidad mayor, parte de esta problemática parecería analogable - en palabras de Blumenberg- a lo que suele ocurrir en el curso histórico, "en donde las épocas se van reemplazando unas a otras con la conciencia de que ahora, por fin, después de

31 Laclau (2006, p. 16).

32 Bosteels (2007, pp. 64-5) énfasis agregado.

33 Laclau (2006, p. 15) énfasis agregado. 
tanta frivolidad en el derroche de las mejores posibilidades del hombre, la cosa va en serio, de que ahora, por fin, se va por el todo"; o, en todo caso, de que se puede desprender uno del modo precedente y acceder a un punto justo -la seguridad, dicho elegantemente, de lo contemporáneo con respecto a su propio tiempo. 34 Otra modalidad de la crítica a este enfoque, y que es la que se ha podido poner en juego a partir de las polémicas entre Laclau y Žižek de fines de los ' 90 en adelante, se orientaría a indicar que desde interior de su propio suelo discursivo la redefinición no logra desprenderse sin un "pasaje" subjetivo, y por lo tanto, la distorsión se desplaza a la reflexividad, con lo que la crítica se autoanula. Pero pasemos ahora a nuestro último punto -"metafórico"- de aproximación, en el que podremos extender algunas de las matizaciones y reflexiones.

No sin antes recordar una conclusión blumenbergueana respecto a nuestra "situación", en el marco de uno de sus trabajos más explícitos a la hora de reflexionar sobre este plano, o dimensión, temporal: "la retórica enseña a reconocer la retórica, pero no enseña a legitimar la retórica". 35

\section{Metafóricas de fondo y problemática ideológica}

Veamos por último, a una intervención de M. Jay que aparecerá en un ángulo particular de refracción con respecto a varios puntos de los anteriormente mencionados.

En su "Ideología y ocularcentrismo" Jay parte de una descripción del modo en que el sentido de la vista ha sido la metáfora preferida para representar la verdad en la "tradición occidental" (la cual puede encontrarse ya en Platón, pasando por Descartes y así sucesivamente). ${ }^{36}$ Este "ocularcentrismo" observa Jay, habría entrado en crisis en el siglo XX, junto con lo cual el binomio "visión falsa o invertida/visión verdadera" habría perdido también sus credenciales teóricas. Esta composición del campo de las metáforas de la sensibilidad imperantes en distintos momentos históricos le permitiría a Jay observar de qué manera el empleo que hace Marx de la figura de una "camera obscura" -en un contexto de pleno auge ocularcéntrico- para ilustrar su noción de ideología, le habría insuflado una fuerza retórica significativa.

Aprovechando este campo de perspectivas diversas sobre el tema, se podría observar, por ejemplo, que en caso de incorporar al interior del planteo de Jay a la postura de Žižek - preocupado por "la relación entre lo visible y lo no visible"cabría eventualmente la conclusión de encontrar al pensamiento de éste operando

\footnotetext{
34 Blumenberg (2003, p. 668).

35 Blumenberg (1999, p. 134).

36 Jay (2003, pp. 253-73).
} 
sobre aspectos en algún punto anacrónicos. Inversamente, si observáramos al texto de Jay bajo la luz del relato de Žižek, debemos destacar que aquel se preocuparía por tematizar sólo una de las tres dimensiones de la ideología: la "doctrinal".

De todos modos, el texto de Jay parte del mismo interrogante de fondo subyacente a las propuestas anteriormente observadas: la pregunta por la viabilidad de un sostén conceptual de la noción de ideología -y por lo tanto de su posible "crítica" en el horizonte contemporáneo. Pues cabría preguntarse, acorde a esta secuencia, si la única opción que quedaría sería dirigir la mirada hacia los puntos ciegos, las aporías y tensiones que atraviesan y subvierten a toda fijación; si la tarea actual de la ideología sería devenir en centinela invisible recorriendo la textualidad al resguardo de su imperio, el de la iterabilidad infinita; la ideología como asedio, como filo que hiende y disecciona todo esfuerzo de fijación absoluta desde sus mismos presupuestos.

La línea argumentativa seguida por Jay en relación a esta problemática será parcialmente inversa a las anteriormente observadas. El campo de la desconstrucción quedará debilitado mientras que el horizonte habermasiano se mostrará al menos como un terreno menos blando -según Jay- para la construcción de una nueva norma que permita delimitar la distorsión ideológica. Parafraseando a Lacan, Jay distingue entre la necesidad de renunciar a un Otro, con mayúscula, visual de la ideología, pero se pregunta por la posibilidad de encontrar al menos algunos "otros" no visuales que nos permitan sostener la categoría crítica. La alternativa, una vez que la visión ha perdido sus garantías de confiabilidad, normalmente ha sido, según Jay, la de indagar la esfera del lenguaje. En ese orden de ideas, el autor distingue dos tendencias contemporáneas -con distinto énfasis en los fenómenos del lenguaje- y que se propone analizar: la desconstrucción y la hermenéutica crítica.

Con respecto al primer caso, el autor tematiza algunas variantes como el perspectivismo radical nietzscheano de S. Kofman y la ausencia total de la noción de ideología en R. Gasché, para detener su atención en la obra madura de P. de Man: "Lo que llamamos ideología -según De Man- es precisamente la confusión de lo lingüístico con la realidad natural, de la referencia con el fenomenalismo". ${ }^{37}$ Lo "otro" de la ideología se encontraría entonces vinculado, en este caso, a la superación de tal confusión. Pero esto, según observa Jay, se debilita notablemente si consideramos que una de las principales lecciones de la desconstrucción ha sido la de que nunca podemos establecer una clara distinción (en este caso, entre realidad lingüística y extralingüística) "Nuestro conocimiento de la naturaleza [...] es desde siempre lingüístico en el sentido fuerte del término". 38

En suma, este autor encuentra en la imposibilidad de un punto de vista arquimédico que se deduce de un enfoque postestructural una debilidad teórica ineludible a

37 Paul de Man, The resistance to theory, Minneapolis, 1986, en Jay (2003, p. 262).

38 Jay (2003, p. 263). 
la hora de ofrecer una alternativa viable para una "critica-ideológica" y encuentra en el mismo - a pesar de reconocer enormes méritos en la desconstrucción a la cual toma como uno de sus propios campos de interés-ciertas consecuencias cuestionables: "Mientras no haya una noción más desarrollada de lo que no es una aberración ideológica, quedará siempre la sospecha de que la desconstrucción puede ser corrosiva, no sólo de las mistificaciones, sino también de cualquier alternativa positiva posible" pudiendo volverse aún en contra de muchos de los valores por los cuales los grupos oprimidos creían estar luchando. ${ }^{39}$ Por lo tanto, y dado que Jay no se resigna a que la ideología asuma simplemente el viejo programa formalista de desnudar el artificio, este autor se empeña en encontrar una alternativa crítica-ideológica viable en el horizonte habermasiano.

Claro que para eso deberá introducir la ideología en el marco de las interacciones comunicativas intersubjetivas. La concepción de Habermas, como es sabido, postula como un telos teórico el supuesto de una situación de habla no distorsionada en la cual la fuerza del mejor argumento -y no la distorsión o manipulación- sea la que cree los consensos de opinión cognitiva y normativa. Esta situación ideal, en la cual podría resolverse "racionalmente" cualquier conflicto de interpretaciones debe estructurarse en reglas y procedimientos que permitan el intercambio no restringido de opiniones. La distorsión en este contexto sería igual a la alteración con respecto a esta situación de racionalidad comunicativa -lo cual impediría "sistemáticamente" que puedan establecerse relaciones simétricas de poder. Si bien Jay reconoce que estas consideraciones sumariamente desarrolladas dejarían numerosos aspectos que deberían problematizarse, y efectúa diversas salvedades, cree ver en esa alternativa "un ventajoso punto de vista" para decir que la ideología es una aberración. "En otras palabras, la crítica de la ideología sólo es significativa cuando no se limita a poner en evidencia el artificio y a subvertir el saber recibido, sino que se opone a las condiciones que en primer lugar, tienen necesidad de la ideología". 40 Sin embargo una vez que se ha aceptado -como el propio Jay ha reafirmado- que no existe situación no mediada lingüísticamente ¿qué podría entenderse por aquello que "tiene necesidad de la ideología" en orden a una salida que permita una delimitación entre lo ideológico y su otro? Incluso se podría sospechar de una cierta variabilidad semántica entre al menos dos campos de la noción en cuestión, el primero, al interior del horizonte de Habermas, y el segundo, que aparece al final de la oración, y que podría articularse al sentido clásico de la ideología -manteniendo por lo tanto con el mismo una relación ambigua en el contexto donde intentábamos avanzar más allá de sus complejas implicaciones.

Por otra parte, la argumentación de Jay llegaría en cierto momento a la siguiente conclusión: "Aunque el punto de vista de una exterioridad total es, por supuesto,

39 Jay (2003, p. 266).

40 Jay (2003, p. 268). 
una ficción [...] este 'como si' sigue siendo, sin embargo, un útil concepto para nuestro intento de comprender las restricciones estructurales más amplias que limitan nuestra interacción comunicativa". ${ }^{41}$ Resulta interesante esta nueva apelación a un punto de vista arquimédico "inaccesible" -en tanto constante que hemos visto en diversos contextos- no sólo por su similitud con la propuesta de Žižek, sino porque de algún modo estaría abriendo la puerta a la introducción de la desconstrucción como un enfoque perfectamente "viable". Es decir, en caso de estar permitido un "como si" para ejercer una crítica-ideológica, la desacreditación que hace Jay de dicha alternativa deja de tener un verdadero sustento.

Resulta importante destacar un punto en contraste con un cierto gesto bastante común en esta clase de reflexión y que en este caso ilustraremos a través de otro texto de Žižek. Haciendo referencia a la operación de "crítica ideológica" (utilizando esta vez la metáfora del "fantasma" lacaniano) Žižek ejemplifica el movimiento de develamiento del carácter histórico de los orígenes de una formación (por ejemplo: el sistema capitalista) a través de un "atravesar" el fantasma (revelando el carácter contingente de dicho origen). Es decir, propone "denunciar la narración mítica por medio de la cual el sistema sincrónico organiza retroactivamente su propio pasado, sus propios orígenes, y hacer visible la realidad contingente llena de sangre y fuerza bruta". 42 Sin embargo -según afirma Jay- y como bien lo sabía Bretch (a pesar de que algunos de sus seguidores lo han olvidado) "la exposición de las operaciones de la ideología no basta por sí sola para debilitarla realmente; esto sólo se consigue cuando se cambia la constelación más amplia de fuerzas que la hacen necesaria"; 43 punto que en tales reflexiones habría de ser relevante y que orienta la atención hacia el estudio de los mecanismos que permiten una composición y recomposición en las conformaciones, pues no todos los esfuerzos tienen la misma posibilidad de acceso o irrupción y en un mismo nivel. ${ }^{44}$ Este sería el momento en que la pregunta por los mecanismos de significación social sería también aquella por las formas en que en cada campo cualitativo se hace posible la (des)estructuración de su conformación, la reocupación de posiciones fundamentales, teniendo en cuenta el hecho de que no toda otra opción tiene la misma potencia-lidad. A su vez, ¿puede encontrarse en el carácter social del sentido (habitado por las lógicas de imposibilidad y necesidad) junto a los principios de irreversibilidad temporal, algunas pautas para vislumbrar el carácter de una crítica ideológica inmanente? Si la articulación de este principio epistémico y la necesidad o factici-

\footnotetext{
41 Jay (2003, p. 269).

42 Žižek (2006, p. 276).

43 Jay (2003, p. 266).

44 En un sentido similar se expresaría Chakrabarty (1999) en el contexto de reflexión poscolonial al indicar que, el sólo hecho de ser demostrable el carácter imaginario de una cierta construcción de "Occidente", no conlleva necesariamente a la disminución de su atractivo o fuerza.
} 
dad del sentido (social) operaran como reaseguros que evitan al menos la caída en el relativismo radical, esto podría llevar a enfocar en los "órdenes en movimiento" que regulan las posibilidades cualitativas de ciertos desplazamientos.

Por otro lado, hay que destacar que el eje del estudio de Jay gira en torno al par "ocularcentrismo/superación del mismo e inclinación hacia el lenguaje", lo cual no deja de ser en alguna medida problemático. Según hemos observado, el autor estructura su argumento a partir de la primacía ocular clásica y su posterior desacreditación en el siglo XX -lo cual habría impactado en la noción tradicional de ideología. Con respecto a esta última, el eje explicativo visual es ambiguo no sólo porque la noción del marxismo estaba a su vez -en tanto que ocularcéntrica- íntimamente ligada a las posibilidades de articulación semántica en el paso de una conciencia falsa hacia una verdadera. Un ejemplo dentro de esa tradición -si bien en el contexto de Lenin- estaría dado por la importancia que "la explicación paciente" tenía con respecto a las posibilidades de conciencia. Recordemos incluso la afirmación observada de que "todo conocimiento" -si se nos permite la extensión- "es siempre lingüístico en sentido fuerte". Por el otro frente, todos los desarrollos contemporáneos de la ideología centrados en el lenguaje tampoco parecen ser pasibles de aceptar la división en sus preocupaciones por la ideología con respecto a la visibilidad. Alcanzaría tal vez con revisar los ejemplos de los otros autores mencionados en este trabajo -aunque también sea factible encontrar numerosas alusiones más amplias como la de "experiencia" o "sensibilidad" (Rancière hablaría de una reconfiguración de lo sensible), etc. Parte de estos problemas en el texto de Jay estarían ligados al doble sentido que en su texto asume el término "ocularcentrismo" -como primacía metafórica de la visión en su vinculación a la verdad sobre los otros sentidos y como posibilidad de un desdoblamiento entre visión verdadera y falsa. Esto permite realizar el encadenamiento entre el debilitamiento del ocularcentrismo y la "crisis" de la crítica de la ideología.

\section{Notas conclusivas}

Hasta aquí, se ha podido poner de manifiesto y explorar algunos de los problemas que una comprensión del concepto de ideología presenta en el contexto de presupuestos que definen al horizonte contemporáneo. Se han tomado una serie de casos particularmente ilustrativos para dar forma al planteo de su permanente problematicidad, o in-aprehensiblilidad conceptual última.

En otras palabras, el presente constituye un estudio que permite indagar en una dimensión puntual dentro de la literatura del tema, la cual, como es notorio, se avoca al análisis de fenómenos que continúan presentándose como particularmente relevantes y complejos en el seno de las sociedades contemporáneas. 
Bajo el recorrido observado, el análisis ha conducido entonces a poner de relieve una serie de tensiones que se manifiestan en los discursos teóricos orientados a definir y hacer uso del concepto de ideología una vez que tales discursos han asumido una serie de premisas que dan forma a aspectos claves del pensamiento contemporáneo -emblemáticamente, en este caso, las premisas derivadas de lo que Laclau y Mouffe llamarían una "rotación intelectual" propia del siglo veinte, a la que nos hemos acercado a través de ejes como el lingüístico, ciertas dimensiones del psicoanálisis, de la teoría crítica y, especialmente, el postestructuralismo.

El argumento conduce, de este modo, no sólo a poner en evidencia dichas tensiones sino a reconstruir el conjunto de coordenadas que le dan forma, permitiendo internarse en sus "efectos" conceptuales, en las particulares dinámicas que las mismas ocasionan en el plano de los discursos teóricos y la reflexión sobre el tema, así como dejar ver que la situación de dicho límite para lo plenamente conceptuable reactiva aspectos de un horizonte de compresión más vasto dentro del cual, por decirlo en términos de Palti, "aún nos encontraríamos inmersos".

Planteado en términos generales, ha de recordarse que a partir de las contribuciones del marxismo clásico al pensamiento político, la noción de ideología había quedado particularmente ligada -conceptualmente- a la posibilidad de su "opuesto", es decir, a la eventualidad de una perspectiva "no distorsionada", "verdadera" en sentido fuerte, "clara" hacia las cosas y el mundo. Como es sabido, la serie de premisas sobre las que se apoyaba esa idea de Verdad con mayúscula -y junto con ella, la creencia en una posible instancia de tranquilidad, o reaseguro último- habrían sido notablemente cuestionadas en el curso del siglo recientemente pasado. El lugar o la función que ocupaba antaño la verdad, dicho sintéticamente, habría quedado vacío. En concreto, el tipo de pregunta que ha dado forma al objeto del presente trabajo adquiere su consistencia a través de un posible análisis de los modos en que el concepto de ideología y la viabilidad de una operación de crítica-ideológica han sido concebidos, o reformulados, una vez quebrado su antiguo contraconcepto. Esta característica llevaría a sugerir la existencia de una cierta condensación en la temática ideológica de un particular interés histórico-conceptual y epistémico.

Se podría destacar, para concluir, que el concepto de ideología en un horizonte contemporáneo, si observamos los desarrollos analizados, se presenta como algo que no se puede eliminar sin más; no obstante, al mismo tiempo, resulta imposible de aprehender sintéticamente, o conceptualizar.

Se estima, en definitiva, que este trabajo pueda servir como punto de partida para un estudio más amplio sobre el tipo de problemas indicados, así como proveer ciertas claves de interés para la reflexión de aspectos conceptuales, filosóficos o socio-políticos -según el caso- a la hora de enfrentarse o internarse en la indagación de los fenómenos ideológicos. 


\section{Referencias bibliográficas}

BAdiou, A. (2003): El ser y el acontecimiento, Buenos Aires, Manantial.

Benjamin, A. ed. (1989): The Lyotard Reader, Cambridge MA, Blackwell.

Blumenberg, H. (2003): Trabajo sobre el mito, Barcelona, Paidos.

Blumenberg, H. (1999): Realidades en que vivimos, Barcelona, Paidos.

Bosteels, B. (2007): Badiou o el recomienzo del materialismo dialéctico, Santiago de Chile, Palinodia.

ChAKRABARTY, D. (1999): "La poscolonialidad y el artilugio de la historia: Quién habla en nombre de los pasados 'indios?", en Dube Saurabh, ed. Pasados Coloniales, México, 1999.

De SAntos, B. (2006): La fidelidad del olvido. Notas para el psicoanálisis de una subjetividad militante, Buenos Aires, El cielo por asalto.

JAY, M. (2006): Songs of experience. Modern American and European variations on a universal them, California, University of California Press.

JAY, M. (2003): "El enfoque textual de la historia intelectual", en Campos de fuer$z a$, Entre la historia intelectual y la crítica cultural, Buenos Aires, Paidos.

Koselleck, R. (1993): Futuro Pasado. Para una semántica de los tiempos históricos, España, Paidos.

Laclau, E. y Mouffe, C. (2006): Hegemonía y estrategia socialista, Buenos Aires, FCE.

LaClau, E. (2006): Misticismo, retórica y política, Buenos Aires, FCE.

Palti, E. J. (2005): Verdades y saberes del marxismo. Reacciones de una tradición política ante su crisis, Buenos Aires, FCE.

Palti, Elías (1998): Giro lingüistico e historia intelectual, Bernal, Universidad Nacional de Quilmes.

SKINNER, Q. (2007): Lenguaje, política e historia, Bernal, Universidad Nacional de Quilmes.

SkinNER, Q. (2005): "On Intellectual History and the History of Books", en Contributions to the history of concepts, $\mathrm{N}^{\mathrm{o}} 1$, vol.1.

StaVRAKAKIS, Y. (1999): Lacan and the political, London and New York, Routledge.

VILlaCAÑas, J. L. y OnCINA, F. (1997): "Introducción", en Reinhart Koselleck y Hans-Georg Gadamer, Historia y Hermenéutica, Barcelona, Paidos.

ŽIžEK, S. (2006): Porque no saben lo que hacen, Buenos Aires, Paidos.

ŽıžEK, S. (2003a): El sublime objeto de la ideología. Buenos Aires, Siglo XXI.

ŽıžEK, S., ed. (2003b): Ideología. Un mapa de la cuestión. Buenos Aires, FCE.

Matías González

Universidad de Murcia

fermatgon@gmail.com 